\title{
RECURSOS TERMINATIVOS EN EL RELATO CINEMATOGRÁFICO
}

\author{
Emeterio DIEZ \\ Universidad Antonio de Nebrija \\ ediez@nebrija.es
}

Resumen: El artículo da cuenta de la riqueza y complejidad de los mecanismos empleados para cerrar el texto cinematográfico, tanto en el plano de la historia como del discurso, además de mostrar las diferencias entre los finales de las estructuras narrativas cerradas y de las estructuras narrativas abiertas.

Abstract: The article studies the variety and complexity of the mechanisms used to close the film text in the levels of the story and the discourse and inside closed narratives and open narratives.

Palabras clave: Relato cinematográfico. Final. Desenlace. Clímax. Catástasis. Cierre.

Key Words: Cinema Narrative. Resolution. Climax. Catastasis. Clousure. 
En los comienzos del cine, el final de una película venía determinado básicamente por la cantidad de negativo que la cámara era capaz de contener, de modo que la proyección terminaba cuando el rollo, de unos 17 metros (unos 20 segundos), llegaba a su fin. Pero en cuanto el cinematógrafo se convierte en un nuevo medio de contar historias, el final pasa a ser un momento narrativo privilegiado lleno de incógnitas: ¿En las últimas imágenes es cuando todo lo narrado cobra sentido? ¿El cierre es lo que deja mayor resonancia en el espectador? ¿La calidad de una película depende de su final? ¿La espera de ese momento es lo que engancha al público? Aunque añadiésemos todo tipo de matizaciones, estoy seguro de que la mayoría de nosotros (críticos, profesionales o, simplemente, espectadores) respondería de forma afirmativa a estas preguntas. Al menos, así lo harían Aristóteles y sus seguidores. La Poética pide que las fábulas no terminen en un punto tomado al azar, ni que el final sea irracional, sino necesario y verosímil (Aristóteles, 1988: 58). En especial, ataca el «deus ex machina», hoy sinónimo de cierre artificial e incongruente. Francisco Cascales, por su parte, escribe en el siglo XVII: «porque muchas veces acaece perderse toda la hermosura de la Fábula, por andar flojo el Poeta en la solución» (2006: 342).

En estas páginas, vamos a tomar conceptos teóricos de la Dramaturgia, la Narratología y la Retórica, con especial incidencia en las investigaciones de Paul Ricoeur (1995), Marco Kunz (1997) y el texto pionero de Frank Kermode (2000), para estudiar, en el ámbito cinematográfico y desde un punto de vista poético, un aspecto muy concreto de esta cuestión: qué recursos terminativos se emplean para cerrar el relato cinematográfico, cómo concluye la enunciación de la película. Hasta ahora el cine ha contado con un número limitado de trabajos sobre este tema, como los de Josh Gross (1992), R. Donna Chesher (1992) y Richard Neupert (1995). Y, sin embargo, es un conocimiento que nos parece fundamental para comprender cómo se piensa el cine.

Por supuesto, nuestra pretensión no es establecer un catálogo exhaustivo y completo de los recursos terminativos utilizados en las películas, sino dar cuenta de su riqueza y complejidad. Por otra parte, aunque ejemplifiquemos cada mecanismo de cierre, citando esta o aquella película, hay que tener en cuenta que en el final confluyen varios recursos terminativos a la vez. Por ejemplo: un personaje se aleja en el plano (1), se produce un movimiento rotundo de cámara (2), que termina con un paisaje general de la ciudad (3), mientras entra un narrador que cambia de nivel narrativo (4) y también de modo, pues se manifiesta en forma de texto escrito (5), texto que hace de semimarco en cuanto que ya apareció al principio (6), sube la música (7), 
funde a negro (8), sale el título «The End» (9) y entran los créditos finales (10). Un cierre muy parecido a éste se encuentra en Amores y otros desastres (Love and Other Disasters, 2006).

\section{NIVELES DE COMPOSICIÓN DEL RELATO}

Para comprender la ideación y construcción del final, hemos de partir de la premisa de que todo relato está estructurado, es decir, presenta una concreta organización de los elementos narrativos con el fin de lograr una composición armónica, pues, como dicen las perceptivas, cada parte está subordinada al todo y el todo se define por la interrelación entre las partes. En concreto, el relato presenta tres niveles:

1. Estructura profunda o pensamiento del relato. Se refiere al sentido autorial, cultural y mítico que posee el relato (Diez, 2006: 39). El sentido autorial comprende la construcción de sentido decidida por el autor(es), mientras que el sentido cultural alude a las lecturas efectuadas por el público, ya que, como veremos después, todo texto es una obra abierta, en especial, cuando la distancia temporal o cultural separan al texto y al lector. El sentido mítico, por su parte, manifiesta cómo el relato traspone los mismos motivos del mito o los presenta de forma invertida, expresando igual que él una idea del mundo mediante personajes y argumentos.

2. Estructura superficial o trama del relato. Comprende los sucesos o fábula, los rasgos y los roles de los personajes y la situación, todos ellos «tramados» mediante el conflicto. La fábula, por ejemplo, consta de distintos puntos de acción (incidente desencadenante, puntos de giro, clímax, etc.), organizados en escenas, secuencias, actos y bloques.

3. Estructura discursiva o enunciación del relato. Se refiere a la transmisión narrativa (voz, aspecto, tiempo y modo) del relato y a su manifestación (novela, teatro, cine...).

Todo esto quiere decir que el final se compone partiendo de las decisiones conscientes o implícitas adoptadas al trasladar la estructura profunda del relato (nivel 1) a una trama cuya estructura (nivel 2) puede verse alterada a su vez por la estructura discursiva (nivel 3), en el sentido de que, por ejemplo, el final de la película no siempre es el final de la historia o diégesis.

Por otra parte, la confusión e imprecisión terminológica con la que se estudia el final del relato deriva, en gran parte, del hecho de que manejamos 
toda una serie de conceptos (desenlace, catástrofe, cierre, clausura, etc.) sin saber bien a qué tipo de final se refiere: ¿el de la trama?, ¿el de la enunciación?, ¿el autorial?, ¿el mítico? Quien mejor ha precisado el marco conceptual necesario para estudiar el final ha sido Marco Kunz. En su ensayo, El final en la novela (Kunz, 1997: 28-126), estudia los recursos técnicos que los novelistas emplean para que el lector tenga la sensación de texto acabado. Su primera tarea consiste en definir los términos con los que va analizar dichos finales. En concreto, utiliza seis conceptos (cierre, desenlace, epílogo, apéndice, acabamiento y clausura), que nosotros vamos a utilizar, adaptar y ampliar, dadas las peculiaridades de la dramaturgia audiovisual y de nuestra teoría del relato. De momento, y según los niveles mencionados, hemos de distinguir entre:

1. Desenlace. Es el final de la trama, cuando se resuelven las intrigas planteadas y se cierra la historia o diégesis con una situación estable: victoria o fracaso, maduración o muerte, boda o ruptura, reconocimiento o abjuración... El desenlace comprende, por lo tanto, la resolución del argumento en un punto de acción que llamamos clímax y la presentación de la situación estable mediante otro punto de acción que llamamos punto final.

2. Cierre. Es el final discursivo del texto, la última imagen de la enunciación. La película se cierra con el último plano montado antes del explicit («Fin», «The End», «Eso es todo amigos», etc.) o antes de los títulos de créditos finales. El problema es que el cierre está muy claro hasta dónde va (hasta el último plano), pero no sabemos dónde comienza. ¿El cierre es sólo el último plano? ¿Es la última escena? ¿Las últimas réplicas? Veremos que depende de cada texto.

Como señala Kunz, el desenlace y el cierre no tienen por qué coincidir. Puedo empezar el relato con el punto final, introducir un flash-back para situarme en la situación inicial, continuar el relato desde ahí y terminar con un suceso que cronológicamente está en la mitad de la historia. En otras palabras, el desenlace corresponde al orden de la historia (qué se cuenta: sucesión cronológica de los sucesos protagonizados por unos personajes en unos espacios) y el cierre, en cambio, corresponde a la enunciación (cómo se cuenta: puesta en escena y transmisión narrativa).

3. Acabamiento. Es la obra tal y como el autor la considera terminada. Existen casos de películas en las que, por quedarse inacabadas ( $i q u e$ viva México!, 1932; It's All True, 1942) o bien por hallarse perdidas o 
deterioradas (Four Devils, 1928), resulta complicado determinar cuál es el final decidido por el autor, de modo que, si se proyectan, lo hacen con un final que no es el acabamiento. Así mismo, dado que en el audiovisual la autoría es una cuestión compleja, suelen ser frecuentes los finales que no son el acabamiento que deseaba el guionista o el director, sino el acabamiento del productor o del actor. Es paradigmático el caso de las distintas versiones de Blade Runner, película que cuenta con, al menos (se estrenará pronto otra versión), dos finales distintos: el cerrado de la productora (1982) y el más abierto del director (1992). En definitiva, con acabamiento hablamos del final desde el sentido autorial del relato.

4. Clausura. Se define como la cohesión y la coherencia interna y formal (es decir, estética) de la obra, la cual permite, en especial a partir del final, que el público comprenda el texto de forma completa, además de darle sentido y actualizarlo, pues a menudo se trata de un texto rodado hace muchos años. Incluso el espectador puede interpretar el relato al margen de las intenciones del autor, pues todo texto contiene varias lecturas coherentes. Se trata del final desde lo que llamamos sentido cultural del relato.

5. Kairós. Significa tiempo o instante de claridad (Kermode, 2000: 54). El final es también el momento de mayor resonancia, de mayor calado del relato, cuando comprendemos su verdad, su sentido más hondo, aquello que le dio causa, pues el final impone una concepción del mundo y refleja el espíritu del hombre. Es el final en su estructura mítica.

\section{ESTRUCTURAS ABIERTAS Y CERRADAS}

Ahora bien, las decisiones adoptas al estructurar el relato en sus distintos niveles y finales pueden ser muy distintas según el modelo de texto que hayamos decidido componer. Tradicionalmente, se ha distinguido entre dramaturgias cerradas y abiertas. Nosotros vamos a utilizar esta clasificación sabiendo que, como dice Umberto Eco, en realidad, toda obra artística es una obra abierta o lo es en distinto grado. Depende de si: 1) estamos ante una obra en movimiento, la cual invita al público a narrarla con el autor, como sería el caso de una película interactiva; 2) la película se basa en la poética de la sugerencia, esto es, en lo que comúnmente se conoce como dramaturgia abierta y, por lo tanto, el público debe descubrir el sentido; y 3) la película es 
un texto aristotélico, pero está abierto a múltiples lecturas, ya que, de hecho, cualquier película «en cuanto dotada de valor estético, es abierta. Lo es... aun cuando el artista tienda a una comunicación unívoca y no ambigua» (Eco, 1992: 126). Paul Ricoeur lo expresa así: «una obra puede estar cerrada en cuanto a su configuración y abierta en cuanto a la influencia que puede ejercer en el mundo del lector [...] No es una paradoja afirmar que una ficción bien cerrada abre un abismo en nuestro mundo, en nuestra aprehensión simbólica del mundo» (1995: 404-405). Digamos que la dramaturgia cerrada propone un goce estético renovado y cada vez más profundo de un mensaje unívoco, mientras en la dramaturgia abierta, «el autor quiere que se goce de un modo siempre diverso un mensaje de por sí (y gracias a la forma que ha realizado) plurívoco» (Eco, 1992: 129).

En concreto, la dramaturgia cerrada o aristotélica se caracteriza por un final concluyente y completo. El relato responde a todas las preguntas, los conflictos se resuelven (de forma positiva o negativa) y la premisa ética («el mensaje») queda demostrada. El ejemplo más exagerado de este modelo son los finales a lo Agatha Christie, cuando, por ejemplo, el detective Hércules Poirot resuelve todos los cabos de la trama y nos da todo tipo de explicaciones sobre lo sucedido, como en Muerte en el Nilo (Death on the Nile, 1978). El final cerrado corresponde a un estilo de narrar sustentado en una comunicación indirecta y emocional que busca «el rapto» del público, un estilo basado en la causalidad (final lógico), la verosimilitud (final creíble), la identificación (final empático), la probabilidad (final imprevisible), la anticipación (final vaticinado), la polaridad (final positivo o negativo) y la intencionalidad dramática (final emocionante). Es el modelo narrativo que viene defendiendo Hollywood. Dice Syd Field (1994: 55): «Siempre que se vea una película bien hecha se encontrará con un final fuerte y directo, una resolución bien definida. Los finales ambiguos son cosa del pasado.»

En efecto, hubo un tiempo en el que el cine, fundamentalmente europeo, cultivaba lo que Umberto Eco llama una poética de la sugerencia, esto es, una dramaturgia abierta. Se trata de una forma de narrar que antepone la enunciación al argumento, que huye de las claves de los géneros, que busca el extrañamiento y para ello, incluso, rompe la cuarta pared. Como su nombre indica, utiliza finales abiertos, término que engloba el desenlace parcial, el conflicto irresuelto, el final arbitrario, el remate irónico y cualquier otra solución que exija la participación activa del público, de modo que cada espectador decide o propone su final. Es más, como escribe Kunz, dado que en este modelo la trama pierde peso, «el desenlace cede su lugar privilegiado al 
cierre [...] la reducción de la historia y el debilitamiento del desenlace se compensan con la reivindicación de la textualidad y el fortalecimiento del cierre» (1997: 62-63). Así sucede en la obra literaria de Proust, Joyce, Kafka, Pirandello, Ionesco... y en el cine de Bergman, Jancsó, Antonioni... Todos ellos consiguen que el texto, siempre finito, no lo sea en realidad. Con gran acierto, Guido Aristarco escoge el nombre de Novela y Antinovela para titular su ensayo sobre el cine italiano después del neorrealismo, es decir, el estilo de narrar que, desde 1960, adoptan cineastas como Rossellini, Fellini, Antonioni o Visconti, es un estilo inspirado en «la destrucción del personaje, de la historia, del argumento como conflicto fundamental de las anomias del individuo, reducido a hombre sin cualidades o a cualidades sin hombre» (Aristarco, 1966: 120).

Asimismo, la obra cinematográfica de Antonioni le sirve a Roland Barthes para anteponer la dramaturgia abierta a la dramaturgia cerrada. En concreto, Barthes (2007: 120-124) defiende «la suspensión de sentido». Entiende que el relato es filosóficamente más profundo cuanto más abierta es su construcción de sentido, lo cual supone que el final, lejos de proponer una única y fácil interpretación, desconcierta por sus múltiples y complejos significados. La paradoja es que, para llenar de sentido el relato, éste no debe tener un construcción filosófica clara y bien definida, un sólo y omnipresente sentido, sino todo lo contrario. En eso consiste suspender el sentido, concepto que, a su vez, formaría parte de lo que Umberco Eco denomina «poética de la sugerencia» (1992: 80).

Ahora bien, la dramaturgia abierta se ha descalificado a menudo con el argumento de que genera textos que son producto de la improvisación, el escepticismo filosófico, la falta de creatividad o bien todo ello a la vez. En la película de Fellini Ocho y medio (1963), el personaje que desacredita esta forma de narrar es El Crítico. Insistentemente se opone a que se ruede el guión abierto que Guido Anselmi (Marcello Mastronianni) quiere filmar (que, en realidad, estamos viendo). Dice El Crítico que la vida es complicada, ambigua, sí, pero el artista nunca debe añadir desorden al desorden. Destruir, afirma, es mejor que crear cuando uno no sabe qué está creando. Estamos llenos de palabras e imágenes que no tienen sentido, que vienen del vacío y van al vacío. Es mejor, concluye, reducirse al silencio. En realidad, como dice Paul Ricoeur (1995: 405-419), la crisis de la composición literaria y sus efectos más visibles (el cuestionamiento del cierre y debilitamiento del paradigma de la concordancia en la configuración de la trama), lo que traen es la conversión del final inminente en final inmanente y la sustitución de unas convenciones de composición por otras más sutiles y encubiertas. 
Robert McKee (2002: 65-81), por su parte, llama arquitrama a la dramaturgia aristotélica y distingue dentro de la dramaturgia abierta entre minimalismo o minitrama y antiestructura o antitrama. La minitrama, reduce la estructura clásica a su mínima expresión, en el sentido de que el protagonista es un personaje pasivo, las situaciones apenas cambian, el conflicto es interior y adopta un final abierto: cada espectador decide por su cuenta cuál es la respuesta a algunas de las preguntas planteadas. El minimalismo está perfectamente representado en las películas de Antonioni sobre la incomunicación y la crisis sentimental: La aventura (L'avventura, 1960), La noche (La notte, 1961), El eclipse (L'eclisse, 1962) y El desierto rojo (Deserto rosso, 1964). La antitrama destruye el personaje, el cambio es casual, la acción es expositiva y fragmentada y carece de final, pues pretende invertir los elementos de la estructura clásica, tal y como sucede en Un perro andaluz (Un chien andalou, 1928).

Dado que las formas abiertas se definen en contestación al modelo aristotélico, basaremos nuestra exposición en la dramaturgia cerrada y matizaremos para dar cuenta de las excepciones (minimalismo y antiestructura) que tratan de subvertirlo ${ }^{1}$.

\section{EL DESENLACE}

Componer el final de la trama o desenlace implica tomar decisiones en el orden de los sucesos, los personajes, la situación y el conflicto. Ahora bien, desde una perspectiva aristotélica, la fábula marca el resto de los elementos de la trama o se subordinan a él, de modo que el personaje (su transformación), la situación (su renovación) y el conflicto (su resolución) son, en el último extremo, acción. En concreto, componer la estructura de la fábula significa escoger los sucesos que van a formar parte de la historia y ordenarlos de acuerdo con una serie de reglas o lógica de conexión, como son la comprensibilidad, la verosimilitud, la probabilidad, la identificación, etc. Además, esos sucesos deben trabajarse en el eje sintagmático (relaciones que cada suceso mantiene con el suceso que le antecede y le sigue) y el eje paradigmático (relación que cada suceso mantiene con otros sucesos que podrían haber ocupado su lugar, pero que hemos descartado). Los guionistas suelen llamar a este proceso escaletar el guión. Cada tarjeta o ficha es un punto de acción que recoge lo que Chatman (1990: 46-47) llama un aconte-

1 Richard Neupert (1994: 33) sustituye la clasificación abierto y cerrado por cuatro categorías: texto cerrado, historia abierta, discurso abierto y texto abierto. 
cimiento (un suceso que afecta a un personaje) o bien una acción propiamente dicha (un suceso que realiza un personaje). Los puntos de acción constituyen las unidades mínimas de la fábula y se organizan en orden cronológico, de modo que el último punto de acción recibe el nombre de punto final.

La mayoría de los puntos de acción formarán parte de la trama principal, pero puede haber sucesos correspondientes a las subtramas, esto es, muchos textos contienen líneas secundarias de acción que hacen que el relato necesite de un desenlace múltiple y, por lo tanto, de varios puntos finales. Las perceptivas poéticas aconsejan en tales casos concentrar o abreviar los desenlaces, pues «acabada la principal acción, las demás han de ser acabadas, cuando no sea cosa poca y necesariamente derivada de la principal» (Cascales, 2006: 175). Una película de aventuras, por ejemplo, suele narrar primero el punto final de la trama principal (la llegada con el tesoro, la entrega de condecoraciones al valor, etc.) y deja para el cierre el punto final de la subtrama amorosa, casi siempre en forma de un beso de la pareja protagonista. Algo parecido sucede en Robin de los bosques (Robin Hood, 1938). También encontramos un desenlace múltiple, aunque de otro tipo, en las películas de episodios, como en Le plaisir (1952).

En el modelo hollywoodiense, de dramaturgia cerrada, cada punto de acción es una escena: un suceso en una unidad de lugar y de tiempo. Estas escenas se estructuran en secuencias (conjunto de escenas con unidad dramática), en actos (conjunto de secuencias separadas por un punto de giro) y en bloques (actos que forman el planteamiento, el nudo y el desenlace). Según los casos, los bloques están separados por dos puntos de giro (estructura en tres actos), por dos puntos de giro y un punto medio (el modelo de Syd Field en cuatro actos), por cuatro puntos de giro (estructura en cinco actos), etc. Cada uno de los bloques se caracteriza por la presencia de un punto de acción sin el cual ese bloque perdería aquello que le caracteriza. Así, el planteamiento es el bloque que muestra la situación inicial o prótasis (cuál es el universo temporal y espacial de la obra, qué personajes intervendrán, cuáles son las relaciones entre ellos...), además de introducir el incidente desencadenante (también llamado incidente inductor, alteración, gancho o catalizador). Este último es un suceso que atrapa la atención del público, ya que pone en marcha la historia al fijar una meta en el protagonista, el cual entra en acción física y psicológica. El nudo, por su parte, está lleno de barreras, complicaciones, contraintenciones y se cierra, a menudo, con la crisis. Finalmente, el desenlace contiene el clímax y el punto final o catástasis. 


\subsection{El clímax}

El clímax es el momento de mayor tensión emocional del relato, el punto culminante de la acción dramática, el momento decisorio y crucial, el suceso que responde a la pregunta planteada por el incidente desencadenante. Un relato puede tener tantos clímax como tramas, aunque se valora más el clímax que cierra varias tramas a la vez. Por otra parte, el clímax puede resolverse en una escena o requerir de varias escenas, por lo que unas veces, sobre todo si la escena única es breve, se produce de una forma abrupta, mientras que, en otros casos, se da una forma dilatada.

Suele creerse que si el público adivina el clímax, si sabe cuál será la respuesta a la pregunta central, la película pierde el interés y el público abandona la sala, pero la verdad es que, en ocasiones, se emplea el desenlace anticipado: se sabe por medio de una predicción, un sueño u otro medio qué sucederá, pero no cómo ni por qué. En cualquier caso, la idea de que hay que ocultar y retrasar el clímax ha conducido a esconder el desenlace de la fábula con efectos emocionales como el falso clímax, el suspense forzado y el salvamento en el último minuto.

El falso clímax consiste en dar una respuesta a la pregunta central que inmediatamente, en la escena siguiente, se revela como falsa, es decir, permite introducir otra sorpresa en el último minuto del filme. Un ejemplo muy claro lo tenemos en Terminator 2: el juicio final (Terminator 2: Judgment Day, 1991) con las destrucciones sucesivas del «cyborg» T-1000.

En cuanto al suspense forzado, consiste en ralentizar la llegada del clímax. Por ejemplo, prolongando el momento en el que se le quita la máscara al asesino y conocemos su identidad.

Finalmente, el salvamento en el último minuto alude a la situación en la que un personaje está en peligro y el héroe debe lograr su rescate justo antes de un posible trágico final. Era un recurso muy utilizado en el cine mudo. Por ejemplo, lo encontramos en El nacimiento de una nación (The Birth of a $\mathrm{Na}$ tion, 1915) y en Las tres luces (Der Müde Tod, 1921). Hoy se denomina con el término inglés «final countdown» y casi ha quedado restringido al cine de acción, como en Misión imposible 2 (Mission: Impossible II, 2000).

\subsection{El punto final}

Dado que todo final es, al mismo tiempo, el principio de otra cosa, la dramaturgia cerrada impone, después del clímax o implícito en él, un último 
punto de acción en el que se reflexiona sobre lo ocurrido o, mucho más frecuente, el público conoce el futuro del héroe y de la comunidad por la que éste ha luchado. Se narra, en otras palabras, cómo es la sociedad tras la victoria o la derrota del protagonista, a qué estado nuevo y duradero se ha llegado. En una de sus acepciones, la dramaturgia clásica designa a este suceso con el nombre de catástasis. Nosotros emplearemos el término «punto final». Es un momento fácilmente distinguible, porque, además de ser cronológicamente el último suceso de la historia, representa un momento de acción descendente, incluso cuando la catástasis es el clímax de una subtrama, sobre todo, de la subtrama amorosa.

El punto final sólo es ascendente cuando introduce un suceso inesperado que prepara una segunda parte (denominándose entonces punto de suspensión) o bien cuando coincide con el clímax. Porque, en efecto, el clímax y el punto final pueden converger en una misma escena, es decir, el desenlace termina con una situación en la que, en terminología de Boris Tomachesvski (1982: 184), «todos los contrastes se resuelven y los intereses se concilian». Por ejemplo, La gran ilusión (La grande illusion, 1937) termina con un plano que constituye al mismo tiempo el clímax y el cierre. En ese plano, Maréchal (Jean Gabin) y Rosenthal (Pierre Fresnay) se alejan hacia el horizonte, adentrándose en Suiza y salvando sus vidas tras huir de un campo alemán de prisioneros.

Y cuando el clímax y el punto final no coinciden, la perceptiva cerrada dice que el punto final ha de ser lo más breve posible, apenas una escena después del clímax, porque «la idea de continuar la acción más allá de sus objetivos es una violación de los principios de la acción dramática» (Lawson, 1995: 337-338). Todo cuanto venga después de ese gran efecto dramático que es clímax sólo puede decepcionar. Billy Wilder así lo entendió en Perdición (Double Indemnity, 1944) cuando eliminó la escena de la cámara de gas, pese al dinero y el esfuerzo invertido en ella.

\section{EL CIERRE}

En la mayoría de los relatos, sobre todo en la dramaturgia cerrada, el punto final es, al mismo tiempo, el cierre, un cierre que consiste básicamente en el reparto de premios (esposas, reinos, dinero...), castigos (muerte, castigo del villano...) y moralejas. La dramaturgia cerrada, decíamos, quiere que el final implique una resolución: que el relato termine con una situación entendible y ejemplar. Ahora bien, dos películas con desenlaces idénticos 
(una boda) pueden tener un cierre muy diferente (cada boda posee una puesta en escena peculiar) y dos películas que cuentan historias muy distintas (una trama de policías y otra de amor) pueden tener un cierre con cierto parecido (un plano general de un paisaje urbano), si bien, salvo plagio, no hay dos películas que tengan el mismo cierre. En otras palabras, el cierre pertenece a la esfera de la enunciación. Muestra cómo se ha plasmado audiovisualmente el desenlace e, incluso, si ese desenlace se ha modificado o hasta ha dejado de ser el cierre por efecto de los cambios en la transmisión narrativa: voz, aspecto, tiempo y modo del relato.

Por lo que se refiere a la plasmación formal, de la misma manera que los poetas dramáticos elegían para el parlamento final de la obra determinado tipo de métrica (de estrofa, de verso, de rima, de sílaba...), el cineasta pone un especial cuidado en la plasticidad del último plano, si bien es verdad que casi siempre se repiten una serie de recursos y de tópicos: sube la música o entra un tema musical que subraya la clausura, funde a negro, encadena con el explicit, etc. Por ejemplo, entre los signos de composición del plano, predomina el plano general, sobre todo, en los finales con el héroe alejándose hacia el horizonte. Otras veces el personaje o los personajes avanzan hacia la cámara hasta llegar a negro. En El acorazado Potemkin (Bronenosets Potyomkin, 1925), el barco cruza la armada zarista y, con los marineros rebeldes saludando triunfantes desde lo alto de la cubierta, avanza hacia el objetivo hasta que la proa ocupa todo el plano. También puede darse algún movimiento de cámara significativo: Los padres terribles (Les parents terribles, 1948) termina con un travelling de retroceso y movimiento de cámara como si «la caravana», esto es, la casa continuase su camino alejándose en el horizonte; Aguirre o la cólera de Dios (Aguirre, der zorn gottes, 1972) prefiere un travelling circular sobre la barcaza en medio del río en la que permanece en pie la figura del conquistador (Klaus Kinski); y El manantial (The Fountainhead, 1949) cierra con un travelling ascendente por un rascacielos hasta llegar a la figura imponente del arquitecto (Gary Cooper).

Por supuesto, no vamos a entrar aquí en toda la casuística que puede darse en el plano final dada la compleja combinación de signos audiovisuales que actúan en el cierre: de composición del plano: sonoros, interpretativos, de caracterización, de iluminación y decorado, de montaje... Todo esto por sí mismo merece un estudio. Simplemente recordar que Muerte en Venecia (Morte a Venezia, 1971) recurre a signos de maquillaje, peinado y vestuario para cerrar la película con la decadencia y la muerte del compositor Gustav Von Aschenbach (Dirk Bogarde); En bandeja de plata (The Fortune Cookie, 1966) termina con un gran subrayado musical; La verdadera historia de 
Jesse James (The True Story of Jesse James, 1956) prefiere para el cierre una canción de ciego que da cuenta de la muerte del bandido a manos de un amigo traidor, incrementándose de esta forma su leyenda; y, en cuanto al montaje, además del fundido a negro y del iris, es frecuente subrayar el cierre con el uso de la cámara lenta y con el plano congelado o bien fijo, como en Distrito Apache (Fort Apache, The Bronx, 1981).

Lo importante es que para interpretar el cierre hemos de valorar conjuntamente toda la gama de signos audiovisuales que intervienen. Pensemos, por ejemplo, en todos los cierres que concluyen con un primer plano del protagonista. Pues bien, ninguno de ellos significa lo mismo. La iluminación, la interpretación, la música, etc. que acompañan a ese primer plano es en cada caso distinta. Y lo es porque obedecen a una estructura profunda y una diégesis diferente. No es lo mismo el rostro frío e inquietante del adolescente/anticristo en La profecía (The Omen, 1976) que la despedida agradecida del alumno (Robert Sean Leonard) en El club de los poetas muertos; hay un abismo entre el semblante soñador de Dorothy (Judy Garland) en El mago de $\mathrm{Oz}$ (The Wizard of $\mathrm{Oz}, 1939$ ) y el rostro al borde de la locura de Vincent (Warren Beatty) en Lilith (1964); en Match Point (2005), el semblante de Chris (Jonathan Rhys Meyers) nos revela que se siente culpable, mientras en Fresas salvajes el profesor Isak Borg (Victor Sjoström) asume con tranquilidad la muerte; no es lo mismo la sonrisa tensa del escritor Paul Sheldon (James Caan) en Misery (1990) que el rostro de felicidad de Cecilia (Mia Farrow) ante la pantalla de cine en La rosa púrpura del Cairo (The Purple Rose of Cairo, 1985).

Es más, aunque estudiemos ese plano final en todos sus signos, su lectura puede ser un enigma o bien puede proponernos una interpretación abierta, tal y como sucede en La dolce vita (1960). Se ha dicho que el final de esta película es el simbólico encuentro con el enorme pez raya que mira al protagonista, Marcello Rubini (Marcello Mastroianni). En realidad, el cierre es un primer plano del rostro virginal y sonriente de una adolescente, Paolina, a la que Marcello se niega a saludar (la conoció tiempo atrás), quizás por vergüenza, quizás queriendo evitar que ella forme parte de la vida vacía y depravada a la que se ha entregado tras el suicidio de Steiner (Alain Cuny) o quizás por ambas cosas a la vez, pues, al fin y al cabo, él se diferencia de sus compañeros de juerga en que es consciente del sin sentido de su vida. En concreto, sobre el gesto que Marcello le hace a Paulina para no ir con ella, dice Fellini: No dice «No oigo, no entiendo.» También se podría considerar un gesto de burla: «No te oigo porque no quiero oírte» (Latorre, 1996: 141). 
En realidad, la dramaturgia abierta es la poética que da más importancia al cierre. Parte de la premisa de que lo significativo no es qué se cuenta (la diégesis), sino cómo se cuenta (el discurso), esto es, no importa el desenlace (de la historia), sino el cierre (de la enunciación). Para renovar el relato es preciso modificar su final y lo relevante del final son las manipulaciones estéticas tendentes a suspender el sentido, ya sea mediante cierta plasmación audiovisual (sustancia de la expresión) o, como vamos a ver a continuación, mediante innovaciones en la transmisión narrativa (forma de la expresión).

\subsection{Cierre y transmisión narrativa}

Entre los recursos más utilizados por la poética de la sugerencia para suspender el sentido se encuentran la voz poliscópica, el punto de vista y la «mise en abyme». Respecto a la primera es paradigmático el caso de Rashomon (1950). El crimen que sucede en el bosque es narrado por los tres personajes que intervienen en el suceso (la mujer, su marido y el bandido), además de por un cuarto personaje que dice haber sido testigo (el leñador). Sin embargo, dudamos de que ninguno de los cuatro haya dicho la verdad. El plano final, que nos recuerda que el monje, el estudiante y el leñador se protegían de la lluvia bajo el techado de un templo destruido, ratifica la idea de que la verdad absoluta ha caído. La verdad es subjetiva y compleja, de modo que hemos de ser nosotros quienes interpretemos sus testimonios $\mathrm{y}$, por lo tanto, quienes cerremos el relato. Un empleo similar de la narración poliscópica se encuentra en La condesa descalza (The Barefoot Contessa, 1954) y Las girls (Les Girls, 1957).

En cuanto al punto de vista, hay que tener en cuenta que, cuando una misma historia, que ha sido llevada varias veces al cine, presenta en cada plasmación cierres distintos, puede deberse a tres causas: 1) el incidente desencadenante plantea preguntas distintas y, por lo tanto, requiere un desenlace distinto; 2) existe un mismo desenlace, pero se le quiere dar un cierre (narrativo y audiovisual) distinto; y 3 ) se dan ambas cosas a la vez. Tomemos como ejemplo tres películas basadas en el crimen que en 1959 tuvo lugar Holcomb (Kansas), un suceso que Truman Capote convirtió en una novela. La primera versión cinematográfica, A sangre fría (In Cold Blood, 1967), termina con el cuerpo de Perry (Robert Blake) colgando de la soga, ya que la película se centra en los delincuentes y en su ejecución «a sangre fría». En cambio, Capote (Truman Capote, 2005) e Historia de un crimen (Infamous, 2006) cuentan la historia desde el punto de vista del novelista y, lógica- 
mente, escogen un desenlace diferente, situado más tarde en el tiempo. En concreto, ambas prefieren acabar mostrando los efectos que sobre Capote tuvo esta experiencia, es decir, el hecho de que ya no volvió a terminar otra novela, si bien el cierre de ese desenlace similar es distinto en cada película.

La estructura en «mise en abyme» se halla en La mujer del teniente francés (The French Lieutenant's Woman, 1981) y Moulin Rouge (2001). En la primera, la historia de amor de los «dos actores» (Meryl Streep y Jeremy Irons) termina con su separación, mientras que los «dos personajes» de la película de época que han interpretado disfrutan de un final feliz. Y es ese final feliz de cine, los dos amantes navegando, el que cierra el filme con evidente ironía. Moulin Rouge, por su parte, contiene, cuatro historias encajadas una dentro de la otra. Primero, estamos en un teatro, la orquesta inicia un tema musical y se abre el telón. En un segundo nivel, Toulouse-Lautrec (John Leguizamo) nos canta-narra la historia del escritor bohemio Christian (Ewan McGregor). En un tercer nivel, ese escritor trata de convertirse en novelista contando su historia de amor con una bailarina llamada Satine (Nicole Kidman). Y dentro de esa historia de amor, Christian escribe una obra de teatro para su amada, la cual vemos representar. Pues bien, la película termina en orden inverso. El primer final es el de la obra y concluye con un final positivo: los jóvenes amantes se besan y triunfan frente al sultán. A continuación termina el relato correspondiente a la novela con la muerte de Satine, la cual antes de fallecer le pide a Christian que escriba su historia para inmortalizar su amor. En tercer lugar, dentro del relato de Toulouse-Lautrec, vemos que Christian escribe las últimas frases de esa novela, incluida la palabra «The End», y Toulouse cierra su relato cantando la premisa del filme: «Lo más grande que te puede suceder es que ames y seas correspondido». Finalmente, se cierra el telón y la banda concluye la música. En otras palabras, una vez más se contrapone el final feliz de la ficción (final 1) con el final trágico de la «realidad» (final 2). Es más, el final negativo es, en realidad, un perder ganando (final irónico), ya que la novela inmortaliza ese amor y convierte a Christian en un escritor (final 3). Por último, el cierre del telón debe interpretarse como una clave genérica y como un recurso para aumentar la puesta en abismo, pues nos recuerda que a este lado del telón estamos mirando la pantalla y la ficción ha terminado (final 4).

Ahora bien, si, como hemos visto más arriba, un final aristotélico nunca renuncia a ciertas decisiones sobre la escala de plano, la luz, la música, el montaje, etc. (sustancia de la expresión), tampoco las manipulaciones en la transmisión narrativa tienen por qué ser algo exclusivo de la dramaturgia abierta ni tienen por qué conducir a la suspensión del sentido. La voz, el as- 
pecto, el tiempo y el modo del relato se pueden utilizar también para diseñar un cierre que acentúe el carácter concluso y cerrado del final. Por ejemplo, se emplea la voz narrativa para que un narrador omnisciente señale que estamos en el final y que todo ha acabado, como en Bienvenido Mr. Marshall (1952). Otras veces un narrador diegético aparece al principio de la película, fija un proyecto narrativo y, por lo tanto, somos capaces de detectar cuándo ese proyecto llega a su final, como en Pequeño gran hombre (Little Big Man, 1970). Es lo que Kunz llama saturación. También hay películas que terminan repitiendo (orden y frecuencia de los sucesos) los momentos culminantes del relato o, cuando el desenlace es trágico, algunos momentos felices, como en Thelma \& Louise (1991) y Leaving Las Vegas (1995). Kunz denomina a esto recolección. Así mismo, el cierre se acentúa cambiando de modo. Unas veces se pasa de imágenes figurativas a un texto escrito, como en Más dura será la caída (The Harder They Fall, 1956). Otras veces las imágenes narrativas dan paso a otras que frenan la narración por su carácter descriptivo (un paisaje, un detalle...), como en Malas tierras (Badlands, 1973). Y también puede darse un salto de un diálogo coloquial a otro reflexivo (un discurso, una sentencia, un comentario) o bien de un parlamento dicho a otro leído o cantado. Esta tierra es mía (This Land Is Mine, 1943) termina con la lectura de la Declaración de los derechos del hombre por parte de la profesora (Maureen O'Hara). Y lo que Kunz llama totalización (cierre que trata de resumir, condensar o englobar el texto entero o un particular aspecto de su totalidad) se consigue tanto con la diégesis (reunión final de todos los personajes) como con el discurso (un narrador descifra el valor universal de lo narrado). Así sucede con el largísimo final de la película Nixon (1995).

\subsection{Cierre y acción diegética}

También es muy frecuente construir el cierre recurriendo a la propia acción que los personajes interpretan en la última escena o en el último plano de la película, es decir, el cierre, tal y como señala Kunz, puede reforzarse con un suceso que alude a procesos finales. Son muchas las variantes: la película termina cuando un personaje deja de leer la carta que había servido para iniciar el relato (Carta de una desconocida, Letter from an Unknown Woman, 1948); el cierre coincide con el fin de la grabación de un testimonio (Pequeño gran hombre, Little Big Man, 1970); un personaje muere (Balas o votos, Bullets or Ballots, 1936; Accatone, 1961; Duelo en la Alta Sierra, Ride The High Country, 1962; Empieza el espectáculo, All That Jazz, 1979); un personaje parte, huye o abandona un lugar (Solo ante el peligro, High Noon, 
1952); se sale de una habitación o de un edificio (Carrie, 1952; El buscavidas, The Hustler, 1961); se abre una puerta (Los contrabandistas de Moonfleet, Moonfleet, 1955); se cierra una puerta (El Padrino, The Godfather, 1972; Mi hermosa lavandería, My Beautiful Laundrette, 1985; Uno de los nuestros, Goodfellas, 1990), etc.

Puede darse el caso de que el diálogo contenga vocablos del campo semántico «final» o bien el último parlamento alude a que algo ha terminado y comienza otra cosa. Así, Escalofrío (Frailty, 2002) finaliza con las frases: «La voluntad de Dios se ha cumplido» y «Alabado sea Dios». El cierre de Casablanca (1942) contiene las conocidas palabras: «Presiento que esto es el comienzo de una hermosa amistad».

Otras veces el cierre contiene un marcador temporal de final: se pone el sol al anochecer (El color púrpura, The color purple, 1985), llega el otoño o el invierno, llueve (Sucedió mañana, It Happened Tomorrow, 1944), se produce el final de un plazo fijado (La vuelta al mundo en 80 días, Around the World in 80 Days, 1956), etc.

También se construye el cierre mediante efectos acústicos y visuales diegéticos que dan la sensación de fundido o que disminuyen o aumentan las sensaciones ópticas y acústicas: se apaga una luz (Persona, Manniskoätarna, 1966), el personaje se aleja progresivamente hacia el horizonte (Raíces profundas, Shane, 1953), el personaje se sitúa en un primer plano o ante una superficie que refleja su imagen y le presenta de otra forma, de modo que se produce una modificación de perspectiva con elementos diegéticos (Tiempo de amar tiempo de morir, A Time to Love, a Time to Die, 1958), los personajes aparecen como congelados en una postura (Veredicto final, The Verdict, 1982), suena una campana (La torre de los ambiciosos, Executive Suite, 1954), etc.

En ocasiones, se mezclan varias de estas acciones diegéticas a la vez (como el anochecer y el horizonte en El jardín del diablo, Garden of Evil, 1954) y, de todas ellas, la acción que alude a un proceso final más repetida es, sin duda, la del personaje alejándose a pie, a caballo, en automóvil, en tren, en avión o en cualquier otro medio hacia el horizonte. Aparece en todo tipo de películas, en especial, en el western. Casi siempre el héroe se aleja solo: El ladrón de Bagdad (TheThief of Bagdad, 1940), Pasaje al Noroeste (Northwest Pasaje, 1940), La dama de Shangai (The lady from Shangai, 1947), Estación comanche (Comanche Station, 1960), Harry el sucio (Dirty Harry, 1971), El silencio de los corderos (The Silence of the Lambs, 1991), etc. En otras, el héroe va acompañado de su pareja o su amigo: Sar- 
gento York (Sergeant York, 1941), Colorado Jim (The Naked Spur, 1953), Los pájaros (The Birds, 1963), El graduado (The Graduate, 1967), Tiburón (Jaws, 1975)... Incluso toda la obra de Chaplin suele identificarse con esta forma de final: el vagabundo camina hacia el horizonte, mientras el iris se cierra sobre su figura. Pero, en realidad, buena parte de su producción tiene otra forma de cierre.

\subsection{Cierre y marco}

El marco es otro recurso terminativo que ayuda a construir el final, ya que inserta la historia en una especie de límites. En concreto, Kunz llama marco a cualquier demarcación que relacione el principio del texto con el cierre. En este sentido, existe un marco (un límite paratextual) cuando el relato consta de un prólogo y de un epílogo (lo veremos después) o bien cuando, a la manera de una representación teatral, la película consta de una apertura y de un cierre de telón (La costilla de Adán, Adam's Rib, 1949; Moulin Rouge, 2001). Existe un semimarco (un límite narrativo) si, por ejemplo: 1) el relato introduce al comienzo un flash-back y concluye en el presente de la enunciación (Broadway Danny Rose, 1984); 2) el relato salta de la irrealidad a la realidad, ya sea del mundo de un cuento al presente en el que un abuelo cuenta a su nieto ese cuento (La princesa prometida, The Princess Bride, 1987) o bien pasamos de un sueño a la realidad (La mujer del cuadro, The woman in the window, 1944; Al caer la noche, Dead of Night, 1945; etc.); 3) el relato cambia la situación narrativa, pues identificamos al narrador que comenzó el relato (El beso de la muerte, Kiss of Death, 1947; Río de sangre, The Big Sky, 1952; Mad Max II: el guerrero de la carretera, Mad Max II: The Road Warrior, 1981); y 4) se produce un cambio de narrador o de narratario (en Sospechosos habituales, The Usual Suspects, 1995, descubrimos que Roger «Verbal», el actor Kevin Spacey, no es un testigo de la acción, sino el personaje, Keyser Soze, que lo ha maquinado todo).

También Kunz considera ciertas formas de circularidad como una forma de marco. Por ejemplo: la repetición del título de la película al final de la película (El gato conoce al asesino, The late show, 1977), la apertura y el cierre de un libro (La roja insignia al valor, The Red Badge of Courage, 1951), la repetición del plano que abre la película en el cierre (En busca de el fuego, La guerre du feu, 1981), a menudo con ligeras o significativas variaciones (Ciudadano Kane, Citizen Kane, 1941), y los paralelismo y contrastes en la acción, los personajes o la situación del principio y del final sin que sean la misma escena (Centauros del desierto, The Searchers, 1956). 


\section{EL EPÍLOGO}

En ciertos casos, el epílogo constituye el verdadero cierre del texto, sobre todo cuando remata de alguna manera la historia (epílogo intraficcional). En el teatro, el prólogo y el epílogo servían, respectivamente, de introducción y de despedida de la obra e implicaban la ruptura de la cuarta pared, es decir, en el caso del prólogo, un actor se dirigía al público, solicitaba su atención, presentaba al autor y a la obra y resumía la acción, mientras en el epílogo el actor resaltaba el mensaje del texto o las enseñanzas de la pieza y pedía el aplauso del público. Aquí llamaremos prólogo al punto de acción, casi siempre anterior a los títulos de crédito iniciales o durante ellos, en el que un personaje o un narrador presentan la trama. En Annie Hall, un relator (interpretado por Woddy Allen) nos dice que nos va a contar su historia de amor con Annie. También suele llamarse prólogo al punto de acción fuerte, casi siempre el incidente desencadenante, que se ha desplazado antes o durante los títulos de créditos para enganchar inmediatamente al público. Es lo que en televisión se llama «teaser».

Cuando una película consta de prólogo, suele llevar al mismo tiempo, aunque no siempre, un epílogo, como en Bienvenido Mr Marshall (1952), Cuando Harry encontró a Sally (When Harry Met Sally, 1989) o Edipo, rey (Edipo re, 1967). En concreto, por epílogo entendemos un punto de acción separado del resto de la película por el hecho de que implica una modificación en el discurso, es decir, es un texto escrito sobre la pantalla, son imágenes que se dan al mismo tiempo que los títulos de crédito, es un sueño o se sale de un sueño, es un película dentro de la película, implica un salto en el tiempo, se cambia de género, se rompe la cuarta pared... La noche de los muertos vivientes (Night of the Living Dead, 1968), por ejemplo, tiene un epílogo formado por unas fotografías en las que, mientras se dan los créditos, vemos el sadismo con el que los cazadores de zombis tratan a los cadáveres. Y Barry Lyndon (1975) termina con un cartel donde se lee: «Epílogo. Fue durante el reinado de George III que los personajes mencionados vivieron y altercaron. Buenos o malos, hermosos o feos, ricos o pobres, todos son ahora iguales».

Como señala Kunz, unas veces este epílogo forma parte de la diégesis (epílogo intraficcional) y otras no (epílogo extraficcional). El epílogo intraficcional puede ser adoptar cuatro formas o varias de ellas a la vez:

1. El epílogo consiste en una recapitulación o resumen de la acción, como en Thelma \& Louise (1991).

2. El epílogo es una vista hacia el futuro, esto es, se cuenta qué fue de los personajes y del mundo del relato tras el desenlace, insertando la 
película en un contexto histórico más amplio. American Graffiti (1973) y Primera plana (The Front Page, 1974), por ejemplo, poseen un epílogo formado por los retratos de los personajes principales acompañados de un texto (y en la versión española de una voz superpuesta) que da cuenta de cómo le fue a cada uno. En Todos los hombres del presidente (All The President's Men, 1976) aparecen unos teletipos que sucesivamente nos informan de los sucesos que siguieron desde la proclamación de Nixon como presidente para un segundo mandato hasta su dimisión en 1974.

3. El epílogo constituye una meditación, introduce una moraleja o una sentencia que recoge la idea central del texto: cuál es su sentido y mensaje. Se trata, por lo tanto, de un momento en el que aumenta el sentido filosófico (ideológico, moral, ético) del relato. La mujer pantera (Cat People, 1942) termina con el cadáver de Irena (Simone Simon) y un cartel que incluye las siguientes palabras del libro Holy Sonnets (1618) de John Donne «Pero el negro pecado ha traicionado a la noche eterna. Ambas partes del mundo deben desaparecer». En Guerra y paz (War and Peace, 1956), mientras la pareja protagonista se aleja hacia el horizonte, se superponen las siguientes palabras de la novela de Tolstoi: «Lo más difícil pero esencial es amar la vida, amarla aun cuando uno sufra, porque la vida lo es todo. La vida es Dios y amar la vida significa amar a Dios».

4. El epílogo es un fragmento que está fuera de la acción diegética o en otro nivel narrativo: un sueño, un pensamiento... Así Persona (Manniskoätarna, 1966) se inicia con un prólogo que consiste en unas imágenes de luces correspondientes a los carbones de un proyector cinematográfico que se pone en marcha con dificultad. La película proyectada parece consistir en una serie de imágenes inconexas: cine mudo, sacrificio de una oveja, una mano clavada a un madero, una arboleda, vallas, rostros de personas viejas aparentemente muertas en un depósito de cadáveres... Estas imágenes concluyen con un niño (Jorgen Lindstrom), que también parecía muerto, el cual mira una pantalla y con la mano toca los rostros que aparecen en ella: primero el rostro de la actriz Elisabet Vogler (Liv Ullman) y luego el de Alma (Bibi Andersson), la enfermera. Las dos son las protagonistas de la historia que viene a continuación y que empieza una vez que pasan los títulos de crédito. Cuando se cierra la narración sobre las dos mujeres, volvemos a ver al niño acariciando sus rostros (¿representación de la maternidad que ambas han rechazado?) y comienza el epílogo. Inmedia- 
tamente se rompe la película en el proyector, se apaga la llama que le proporciona luz y termina la película sin que aparezca la palabra «Fin».

En cuanto, al epílogo extraficcional, corresponde al autor (implícito) y suele ser un comentario metatextual, un fragmento que amplía el texto mediante un comentario del propio texto o una reflexión sobre cuestiones generales de arte, filosofía, etc. La serie de televisión Alfred Hitchcock presenta (Alfred Hitchcock Presents, 1955-1962) comenzaba con una presentación del director y concluía con una despedida en la que se comentaba el relato. En Pesadilla (The Strange Affair of Uncle Harry, 1945), después del «The End», aparece un cartel pidiendo al público que, por favor, no cuente el final. Y un caso muy singular y conocido es el filme Andrei Rublev (1966), donde el epílogo está formado por un documental en color que muestra imágenes religiosas del pintor de iconos.

En ocasiones, nos encontramos con un apéndice, es decir, con un paratexto añadido al texto. La novela emplea cartas, certificados, documentos... En el campo audiovisual, el apéndice es muy común en las ediciones en DVD. Aquí existen apéndices con contenido intraficional (por ejemplo, un documental sobre un personaje real de la película, las escenas eliminadas, etc.) y con contenido extraficcional (las críticas de la película, un comentario del director, etc.)

\section{TÍTULOS}

El último recurso terminativo para indicar el final de la película se encuentra en distintas modalidades de carteles o paratextos. Así, el cierre del relato puede anticiparse nombrando las secuencias, de modo que la última contenga un título con alguna palabra del campo semántico «fin». La película En bandeja de plata (The Fortune Cookie, 1966) tiene 16 secuencias con rótulo. La primera secuencia se titula «1. El accidente» y la última, «16. El resultado final».

Pero las formas más corrientes de títulos finales son el explicit y los títulos de crédito. El explicit es un título que indica el final del relato. Existen distintas fórmulas: «Fin», «The End», «Eso es todo amigos», etc. Incluso esas fórmulas dan al relato cierta circularidad al establecer un nexo entre el título inicial (Érase una vez...) y el título final (Colorín colorado...). Bienvenido Mr. Marshall (1952), por ejemplo, comienza con el autobús que llega al pueblo y el cartel de Villar del Campo, mientras un narrador omnisciente 
dice: «Pues, señor, érase una vez un pueblo español...». Casi noventa minutos más tarde, la película termina con las palabras «Colorín colorado este cuento se ha acabado», dichas por ese narrador, mientras se va el autobús del pueblo y aparece el título «Fin».

El explicit puede ser el último recurso terminativo de la película o bien pueden seguirle los créditos finales. Incluso en ocasiones se prescinde del título «The End» y entran directamente los créditos, como en Chinatown (1974) y Huida a medianoche (Midnight Run, 1988). Los créditos (que sólo son realidad extrafílmica cuando aparecen sobre fondo negro) hacen las veces del colofón en los libros, pues si el colofón indica el nombre del impresor y el lugar y la fecha de edición, los títulos de crédito muestran la ficha técnica y artística, los copyright y ciertos textos de tipo jurídico. También pueden incluir dedicatorias: se rinde homenaje a cierta persona, se recuerda a un profesional que falleció durante la producción (Taxi Driver, 1976), se dedica la película a las víctimas de algún hecho luctuoso (Himno de batalla,Battle Hymn, 1957) o bien se determina la relación entre los hechos narrados y la realidad, ya sea por cuestiones de verosimilitud o para evitar problemas legales. Así Distrito Apache (Fort Apache, The Bronx, 1981) termina con un rótulo que recoge la conocida frase: «Los personajes y acciones descritos en esta película son ficticios y la similitud con cualquier persona actual, viva o muerta, es pura coincidencia».

\section{REFERENCIAS BIBLIOGRÁFICAS}

ARISTARCO, G. (1966). Novela y antinovela. Buenos Aires: Editorial Jorge Álvarez.

ARISTÓTELES/HORACIO (1988). Artes Poéticas. Madrid: Taurus.

BARTHES, R. (2007). «Querido Antonioni...». Cahiers du Cinema España $4,120-124$.

CASCALES, F. (2006). Tablas Poéticas. En Antonio García Berrio. Introducción a la Poética Clasicista. Comentario de las 'Tablas Poéticas' de Cascales. Madrid: Cátedra.

CHATMAN, Seymour (1990). Historia y discurso. La estructura narrativa en la novela y el cine. Madrid: Taurus.

CHESHER, R. Donna (1992). «The End». Closing Lines of over 3,000 Theatrically Released American Films. London: McFarland. 
DIEZ, E. (2006). Narrativa fílmica. Madrid: Fundamentos.

ECO, U. (1992). Obra abierta. Barcelona: Planeta-Agostini.

FIELD, S. (1994). El libro del guión. Fundamentos de la escritura de guiones. Madrid: Plot.

GROSS, J. (1992). The Last Word: Final Scenes from Favorite Motion Pictures. New York: Vintage Books

http://www.wgaeast.org/greatest_screenplays, consultada el 20-VI-2007.

KERMODE, F. (2000). El sentido de un final: estudios sobre la teoría de la ficción. Barcelona: Gedisa.

KUNZ, M. (1997). El final de la novela. Madrid: Gredos.

LATORRE, J. M. (1996). El Padrino II / La dolce vita. Barcelona: Dirigido por.

LAWSON, J. H. (1995). Teoría y técnica de la escritura de obras teatrales. Madrid: ADE.

MCKEE, R. (2002). El guión. Barcelona: Alba Editorial.

NEUPERT, R. (1995). The End: Narration and Closure in the Cinema. Detroit: Wayne State University.

RICOEUR, P. (1995). Tiempo y narración II. México: Siglo XXI.

TOMACHESVSKI, B. (1982). Teoría de la Literatura. Madrid: Akal. 